\title{
THE IMPACT OF THE HEAT ACCUMULATION ON ENERGY EFFICIENCY OF BUILDING
}

\author{
Pavel Drábek, Martin Zálešák, Michal Opluštil \\ Tomas Bata University in Zlin of Applied Informatics Nad Stráněmi 451176005 Zlin Czech Republic
}

\begin{abstract}
It is still a lingering practice to classify energy demands of buildings on the basis of thermal insulation properties of the building envelope, although, more aspects, which cannot be ignored, enters to the evaluation. It is necessary to perform the calculation of the impact of each aspect on the basis on thermal response of the room, which varies primarily by the thermal storage properties of construction materials used. This article deals with the possibility of reducing energy use in buildings by knowledge of the thermal accumulation properties of the mass of the structures. This knowledge creates appropriate premises for rational determination of the required thermal conditions for the internal environment under which are the parameters of the heating systems, heat sources, methods of regulation and optimization of the total heat consumption taken into consideration.
\end{abstract}

Keywords: energy demand; heat accumulation; admittance method; thermal inertia; heating system; decrement factor
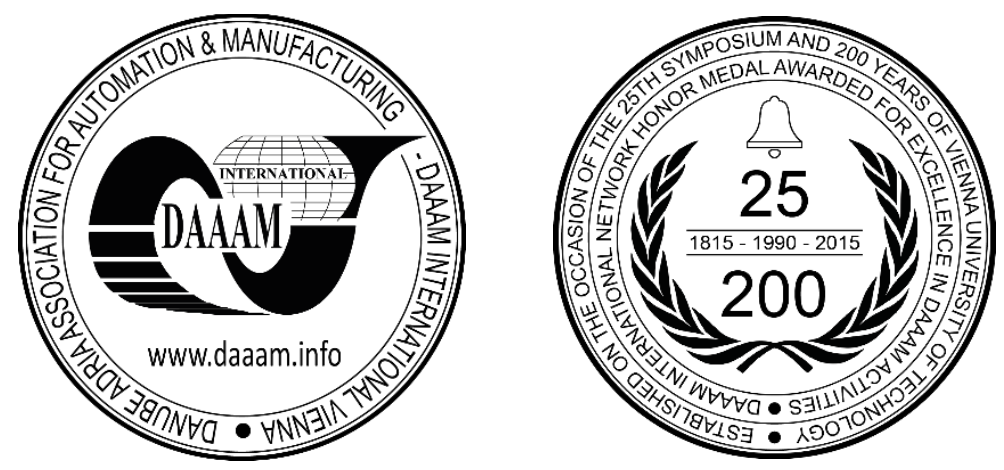

This Publication has to be referred as: Drabek, P[avel]; Zalesak, M[artin] \& Oplustil, M[ichal] (2016). The Impact of the Heat Accumulation on Energy Efficiency of Building, Proceedings of the 26th DAAAM International Symposium, pp.1045-1051, B. Katalinic (Ed.), Published by DAAAM International, ISBN 978-3-902734-07-5, ISSN 1726-9679, Vienna, Austria

DOI: 10.2507/26th.daaam.proceedings. 147 


\section{Introduction}

The calculation of heating and cooling performance of the heating and air conditioning systems in buildings is very important part of buildings design. This part allows us to predict the requirements that will be placed on the energy system. Designing technological systems governing the internal microclimate has to consider appropriate solutions associated with time-varying process of temperatures and heat flows in walls, rooms and entire building. Today, the preferred parameter is the parameter of sufficient thermal insulation which often does not solve the thermal storage capability. Problematic are mainly buildings constructed from lightweight materials, where temperature variations may cause inconsiderable temperature variations of inner wall surfaces which causes discomfort for users [1]. Solving this problem concerns the algorithm of the control of regulation devices. The temperature variations are caused by numerous factors, not only the composition of the walls. Especially it is external air temperature and intensity of solar radiation corresponding to the geographical location and season, absorption of solar radiation, the tilt and orientation of the walls and other factors [2]. Actually under the relevant continental weather conditions the energy performance of the building is evenly influenced by the winter and the summer its behavior, while often one of the two seasons might largely dominate the annual energy demand [1],[3],[12].

Heat accumulation of heated area of the building is one of the most important parameters for design of the HVAC control device [9]. This paper deals with the impact of the heat accumulation to reduce energy needs in an experimental buildings. As a construction material in the evaluated building were chosen three different walls that have the same thermal transmittance (U-value), but different dynamics properties.

\section{Methods used for determination of dynamic thermal properties}

The method used for evaluation is based on the admittance method according to the EN ISO 13786 standard. In the evaluation process are loaded variable boundary conditions for relevant structures. The exact application of this method is explained fully in international standard EN ISO 13786. The admittance method describes the non-stationary heat conduction of outer wall and applications of matrix solution of composite wall. The factors used in this method are based on the assumption that the change of boundary conditions is close to the harmonic waveform [6]. That means that at any location in the component, the temperature variations can be modeled by

$$
\theta_{n}(x, t)=\bar{\theta}(x)+\frac{\hat{\theta}_{+n}(x) e^{j \omega t}+\hat{\theta}_{-n}(x) e^{-j \omega t}}{2}
$$

and the variations of the density of heat low rate are described as

$$
q_{n}(x, t)=\bar{q}(x)+\frac{\hat{q}_{+n}(x) e^{j \omega t}+\hat{q}_{-n}(x) e^{-j w t}}{2}
$$

Therefore, the factors express the relationship of harmonic function which represents the calculation conditions and the resulting harmonic function affected by the effect of accumulation. The relationship of harmonic functions of the temperature in the structure space and time can be described by changing the amplitude of its value in the structure and its time shift. Admittance method is the analytical solution of heat conduction with a harmonious boundary condition [5]. Relationship between variables on the inner and outer surface of the structure are expressed by matrix form

$$
\left[\begin{array}{l}
\hat{\theta}_{2} \\
\hat{q}_{2}
\end{array}\right]=\left[\begin{array}{ll}
Z_{11} & Z_{12} \\
Z_{21} & Z_{22}
\end{array}\right] \cdot\left[\begin{array}{l}
\hat{\theta}_{1} \\
\hat{q}_{1}
\end{array}\right]
$$

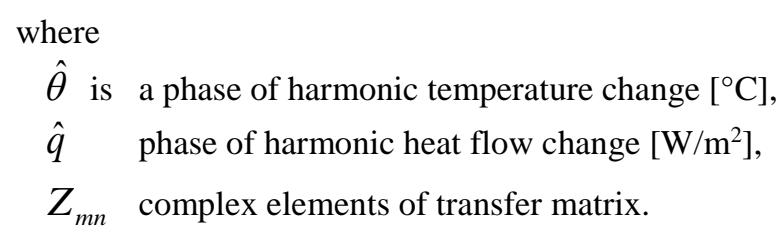

The results of the matrix calculation are two complex values, thermal admittance $Y_{n n}$ and thermal transmittance $Y_{m n}$ which can be expressed by the amplitude and phase shift. Indexes $m$ and $n$ indicate the type of environment, $m$ means an internal environment and $n$ means an external environment. These values allow us to calculate important parameters for comparing the thermal inertia of the structure, which describes [6]. It is the decrement factor $f$ and corresponding time shift $\Delta t_{f}$. 


\section{Parameters of model building}

The purpose of computational analysis was to evaluate three different structures, whose thermal insulating properties meet the legislative requirements on newly constructed buildings. With the current trends in building industry in the Czech Republic were designed the structures of various surface mass. Sandwich type construction typical for timber (C1), wall of bricks of porotherm insulated from the outside (C2) and wall of reinforced concrete with thermal insulation from the outside (C3). is shown in Table 1 (from inner side).

\begin{tabular}{|c|c|c|c|c|c|c|c|}
\hline Wall & \multicolumn{5}{|c|}{ Wall composition } & \multirow{2}{*}{$\begin{array}{c}\begin{array}{c}\text { Total } \\
\text { thickness [m] }\end{array} \\
0,284\end{array}$} & $U\left[\mathbf{W} / \mathbf{m}^{2} \mathbf{K}\right]$ \\
\hline $\mathrm{C} 1$ & Cetris plank & $\begin{array}{l}\text { Thermal } \\
\text { insulation }\end{array}$ & OSB plank & $\begin{array}{l}\text { Termal } \\
\text { insulation }\end{array}$ & Plasteboard & & \multirow{3}{*}{0,210} \\
\hline $\mathrm{C} 2$ & Inner coat & Brick Porotherm & $\begin{array}{l}\text { Thermal } \\
\text { insulation }\end{array}$ & $\begin{array}{l}\text { External } \\
\text { coat }\end{array}$ & - & 0,430 & \\
\hline $\mathrm{C} 3$ & Inner coat & $\begin{array}{l}\text { reinforced } \\
\text { concrete }\end{array}$ & $\begin{array}{l}\text { Thermal } \\
\text { insulation }\end{array}$ & $\begin{array}{l}\text { External } \\
\text { coat }\end{array}$ & - & 0,509 & \\
\hline
\end{tabular}

Table 1. Construction parameters of the wall of the model building

As it is seen from the Table 1, the individual walls are composed of different materials. All constructions are characterized by the same thermal transmittance $\left(U=0,21 \mathrm{~W} /\left(\mathrm{m}^{2} \mathrm{~K}\right)\right)$. Total wall thickness is the only one parameter which is different. Three model buildings, which are dimensionally identical, were made from these walls. The weather station, located at University in Zlin, was used as a source of reference climatic data. Parameters of model building are shown in Table 2.

\begin{tabular}{lcccc}
\hline Type & $\begin{array}{c}\text { Floor area of the inner } \\
\text { space }\left[\mathbf{m}^{2}\right]\end{array}$ & $\begin{array}{c}\text { Internal air volume } \\
{\left[\mathbf{m}^{3}\right]}\end{array}$ & Total heat loss[W] & $\boldsymbol{U}$-value $\left[\mathbf{W} / \mathbf{m}^{2} \mathbf{K}\right]$ \\
\hline House & 89,25 & 547,50 & 8304,00 & 0,30 \\
\hline
\end{tabular}

Table 2. Parameters of the model building

Table 2 shows the total heat loss. This value of heat losses is for all construction therefore almost identical. The slight variations appear here because of different external volume caused by varying the total thickness. Of the total heat loss accounts $17.8 \%$ for peripheral walls, $10 \%$ for the roof, $4.6 \%$ for the floor, $8.8 \%$ for windows and doors, $17.6 \%$ for thermal bounding and $41.2 \%$ for ventilation.

\section{Comparing the thermal inertia of structures}

Dynamic thermal properties of the walls were evaluated by the admittance method mentioned before. The accumulation of the non-stationary heat conduction can achieve substantial delay on heavy walls and it is therefore necessary to assess the heat accumulation in time interval longer than 24 hours [2].The evaluation covers the entire wall thickness.

\begin{tabular}{|c|c|c|c|c|c|c|c|c|}
\hline & \multirow[t]{2}{*}{$\begin{array}{c}\text { Surface } \\
\text { weigh } \\
{\left[\mathrm{kg} / \mathrm{m}^{2}\right]}\end{array}$} & \multicolumn{2}{|c|}{$\begin{array}{l}\text { Heat dynamical admitance } \\
\text { on the inner surface } Y_{11}\end{array}$} & \multicolumn{2}{|c|}{$\begin{array}{c}\text { Heat dynamical admitance } \\
\text { on the outer surface } Y_{22}\end{array}$} & \multicolumn{2}{|c|}{$\begin{array}{c}\text { Dynamical } \\
\text { admitanceof the heat } \\
\text { transfer } Y_{12}\end{array}$} & \multirow[t]{2}{*}{$\begin{array}{l}\text { Decrement } \\
\text { factor } f[-]\end{array}$} \\
\hline & & $\begin{array}{c}\text { Modul } \\
{\left[\mathrm{W} / \mathrm{m}^{2} \mathrm{~K}\right]}\end{array}$ & $\begin{array}{l}\text { Time shift } \\
{[\mathrm{h}]}\end{array}$ & $\begin{array}{c}\text { Modul } \\
{\left[\mathrm{W} / \mathrm{m}^{2} \mathrm{~K}\right]}\end{array}$ & Time shift $[\mathrm{h}]$ & $\begin{array}{c}\text { Modul } \\
{\left[\mathrm{W} / \mathrm{m}^{2} \mathrm{~K}\right]}\end{array}$ & $\begin{array}{c}\text { Time shift } \\
{[\mathrm{h}]}\end{array}$ & \\
\hline \multicolumn{9}{|c|}{ Time period: 24 hours } \\
\hline C 1 & 116,8 & 4,00 & 1,97 & 1,14 & 3,84 & 0,05 & $-11,34$ & 0,237 \\
\hline C 2 & 263,1 & 3,50 & 1,94 & 1,80 & 5,00 & 0,03 & 11,68 & 0,142 \\
\hline C 3 & 810,8 & 5,25 & 0,79 & 1,81 & 5,02 & 0,01 & 10,36 & 0,059 \\
\hline \multicolumn{9}{|c|}{ Time period: 48 hours } \\
\hline C 1 & 116,8 & 3,12 & 5,87 & 0,74 & 7,40 & 0,12 & $-14,28$ & 0,552 \\
\hline C 2 & 263,1 & 2,85 & 4,35 & 0,95 & 9,50 & 0,07 & $-16,50$ & 0,332 \\
\hline C 3 & 810,8 & 4,88 & 1,96 & 0,94 & 9,64 & 0,03 & $-19,08$ & 0,155 \\
\hline
\end{tabular}

Table 3. Dynamics thermal characteristics of structures 
The values in Table 3 contain the parameters needed for revaluating the thermal inertia parameters of structures. Decrement factor describes absorbing thermal waves generated during the passage of heat from one surface of the structure to the other one. The lower value means the higher thermal inertia quality. Thermal admittance indicates how the structure responds to the change of the heat density of the heat flux [5].

According to the values mentioned above, it can be concluded that the highest thermal inertia has the wall C3. The main criterion is the decrement factor $f$ which is more than twice lower than the wall $\mathrm{C} 2$ and almost four times lower than the wall $\mathrm{C} 1$. Another interesting value is the time shift $\Delta t_{f}$ that is the time for which structure responds to the sudden changes of outside temperature or solar radiation. This value is greater than 10 hours for all classified structures. The lowest time shift shows wall C3. The wall with the greatest surface mass has the greatest thermal inertia. It results in the fact that the structure with the greater mass achieves higher delay then the light one. In case of evaluation of a time period 48 hours and more, the wall C3 shows the biggest response time to the sudden changes of outside temperature (Fig. 1). The resulting values may be affected by a certain degree of inaccuracy [8]. According to [7], larger relative errors can be expected with heavy walls in comparison with the light ones.
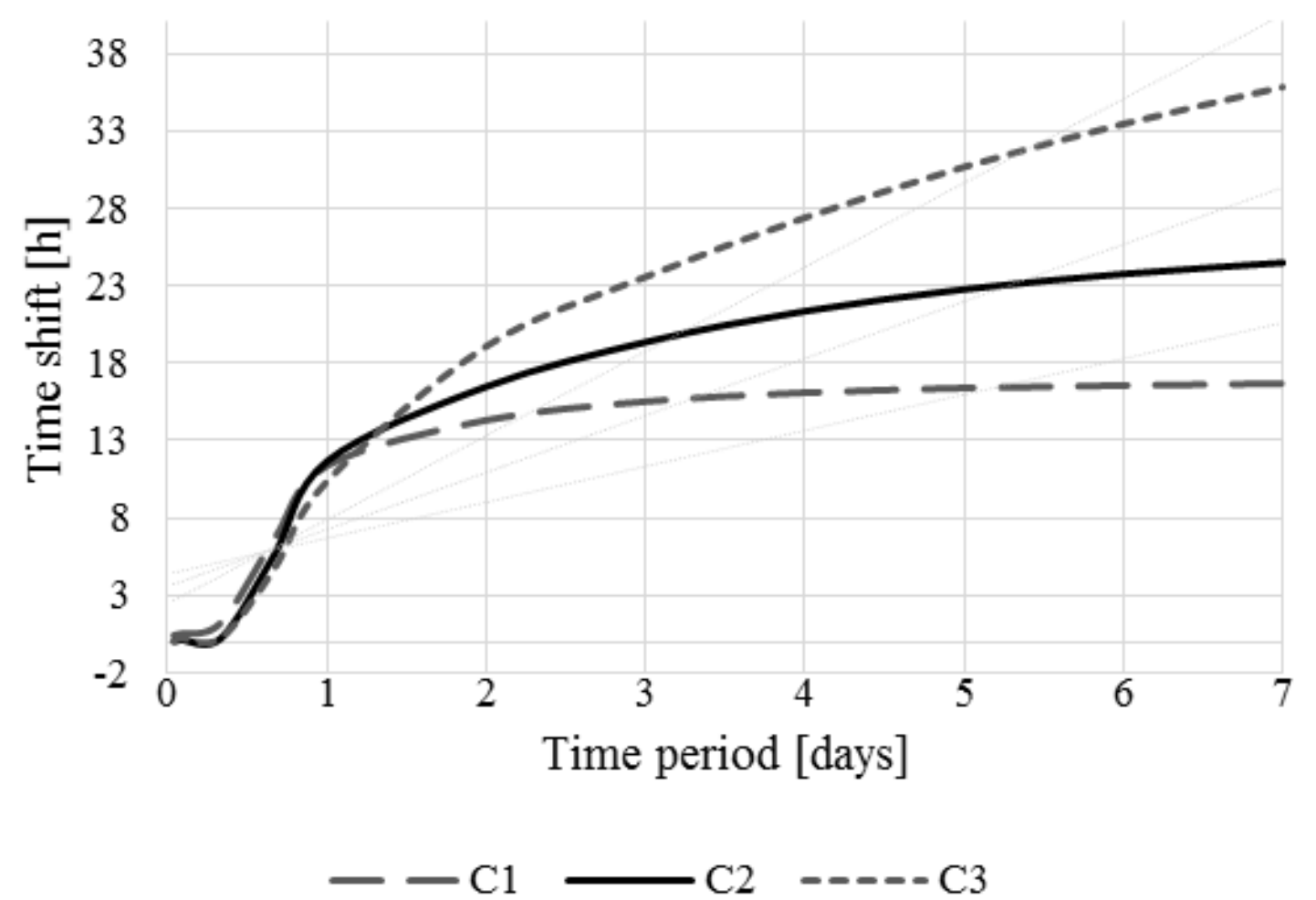

Fig. 1. Time response to sudden changes outside temperature

Heat accumulation can be divided into two parts, due to the non-stationary heat transfer of wall. These two parts are the accumulation of absorbed radiation falling on the inner wall surfaces and the accumulation in the outer wall caused by changes of outdoor temperature and solar radiation [4].

For a more realistic result, the interior space in the building model was separated by walls from the same material as the evaluated peripheral wall. The inner wall surfaces are exposed to the solar radiation passing through the transparent building elements and also to the solar radiation reflected from the other internal surfaces. There was calculated average temperature of outside air for 24 hours cycle, to obtain cyclic boundary conditions. Subsequently, the temperature variation was calculated. The analysis was carried out for one day, with the consideration of heat accumulation from previous days. It included the effect of thermal inertia with an identical number of heat transfer surfaces, sunlight intensity and ventilation, in the evaluation process. As a valuation day was selected Jan. 7, 2015, while the previous three days had a similar temperature course. The average daily operative temperature was $3.26^{\circ} \mathrm{C}$ and during the day the temperature dropped about $7^{\circ} \mathrm{C}$. Inner air temperature was assumed as $21^{\circ} \mathrm{C}$. Solar radiation values were set at hourly intervals by normative recommendations. 

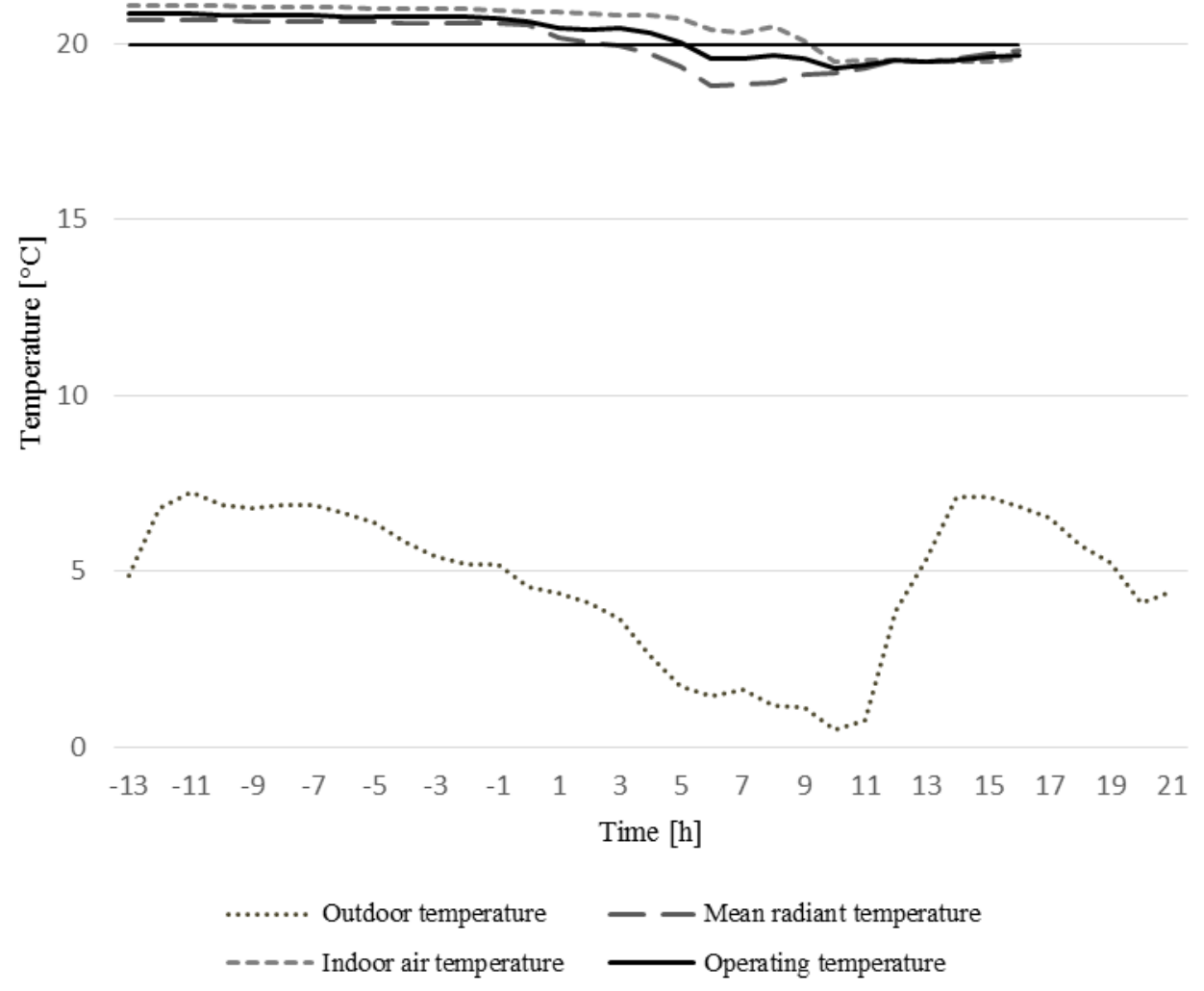

Fig. 2. Temperature curves for model building (C1)

The construction responded with some delay with a noticeable decrease of indoor air temperature. At the model building with walls $\mathrm{C} 1$ was reduced internal operating temperature below the limit of normal level of expectation of comfort for 5 hours. The heating should start at this point.

In the evaluated case modelled by the second building, the internal operating temperature was reduced below the limit of required level of comfort for 6.5 hours.

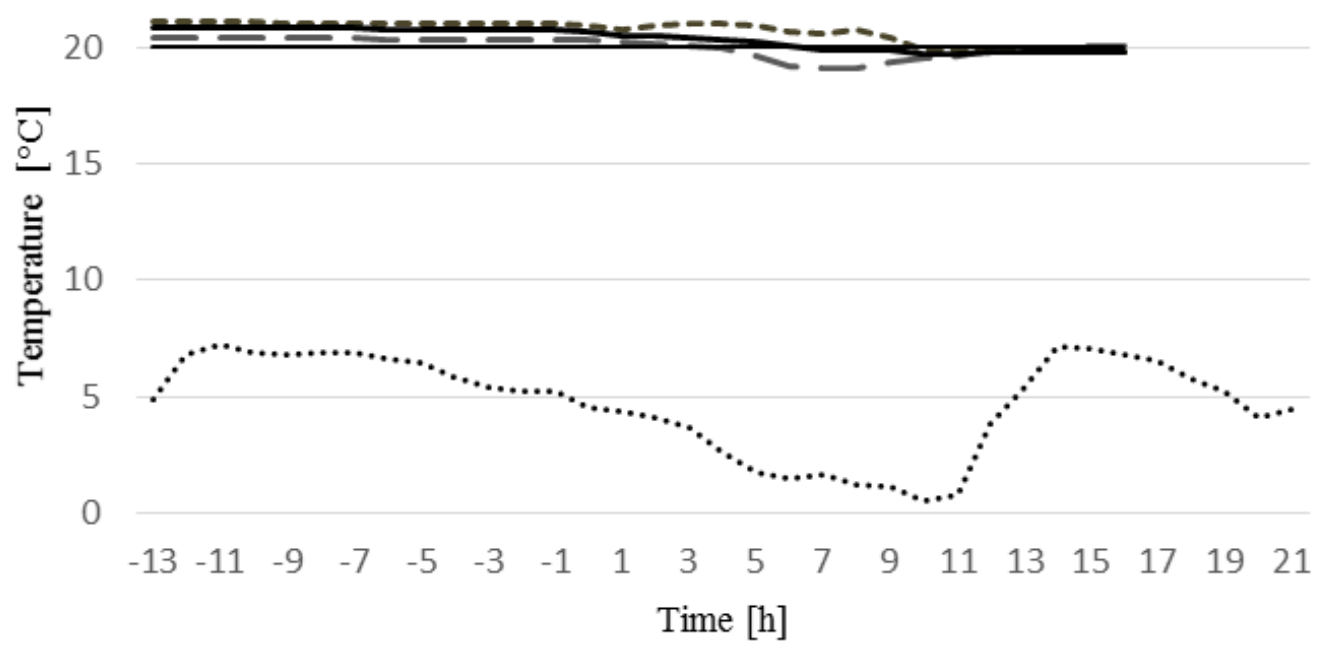

Outdoor temperature

- Mean radiant temperature

- Indoor air temperature

Operating temperature

Fig. 3. Temperature curves for model building (C2) 


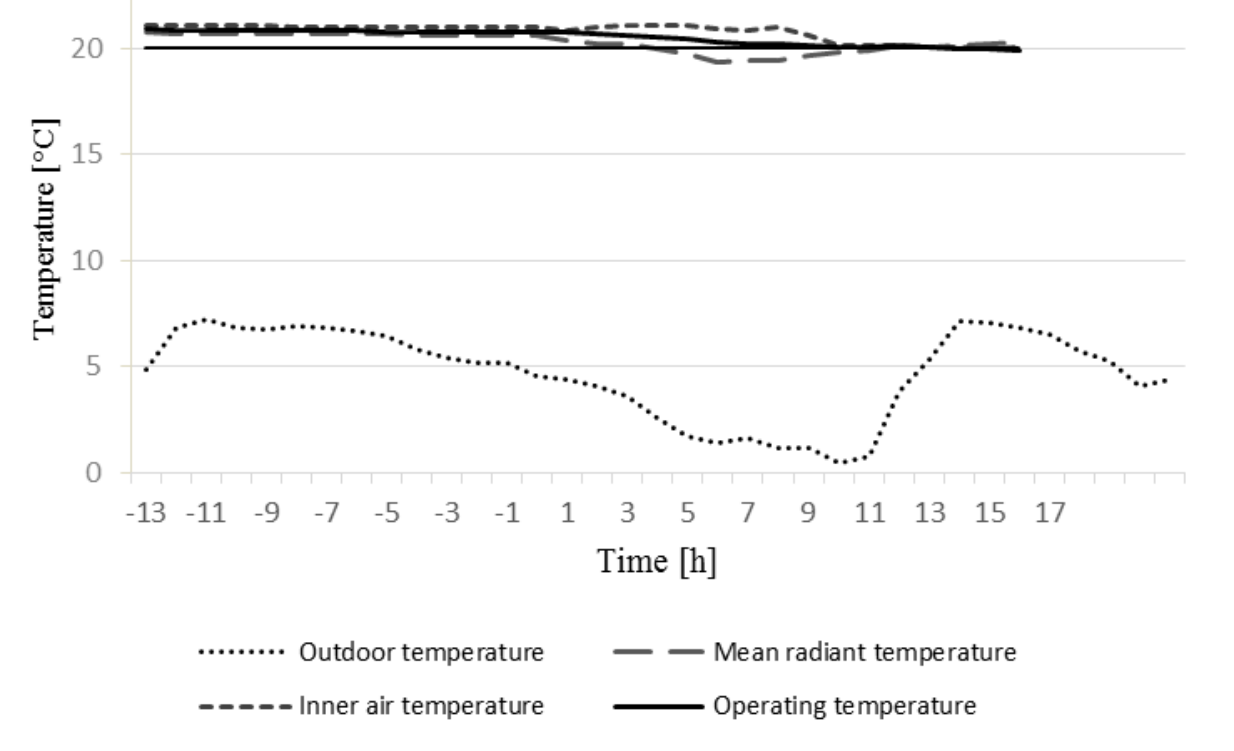

Fig. 4. Temperature curves for model building (C3)

Fig. 4 shows, that the wall with the largest thermal inertia did not decrease below this limit during 15 hours. It can be seen that a higher thermal inertia has a positive influence on the thermal comfort, there is no significant perceptible decrease of the wall surface.

In all model cases it is interesting to observe the curves of the mean radiant temperature of the inner wall surfaces. Especially between 7-8 am, when it starts to increase the intensity of solar radiation. By absorbing of the solar radiation by the outside wall surfaces, the inner surface temperature is rising and it results into the heat flow convection from the inner wall surface into the air. After $12 \mathrm{am}$, the temperature is higher than the inner air temperature. Reaction of the inner wall surfaces on the incident solar radiation is significantly faster than the response caused by the plain heat convection of the outer wall.

\section{Impact of the heat accumulation on energy demand of building}

The resulting values had to be adjusted, to comprise the temperature conditions in the days preceded to the experiment, to be able to compare the course of the internal temperatures under the same conditions [4]. The problem was that the model house from the wall $\mathrm{C} 3$ resulted in the biggest response time and has not been able to accumulate a sufficient amount of the heat. This fact verifies the assertion that the buildings with high heat accumulation have extended heating season, although characterized by lower energy requirements [7]. Fig. 5 shows that the evaluated day will be necessary to deliver the most energy to model building consisting of lightweight construction (wall C1). In these buildings, there is a greater risk of overheating, especially in summer.

For optimum energy consumption for heating it is necessary to choose the suitable type of heating system, while considering heating course based on the thermal storage properties of the building [2].

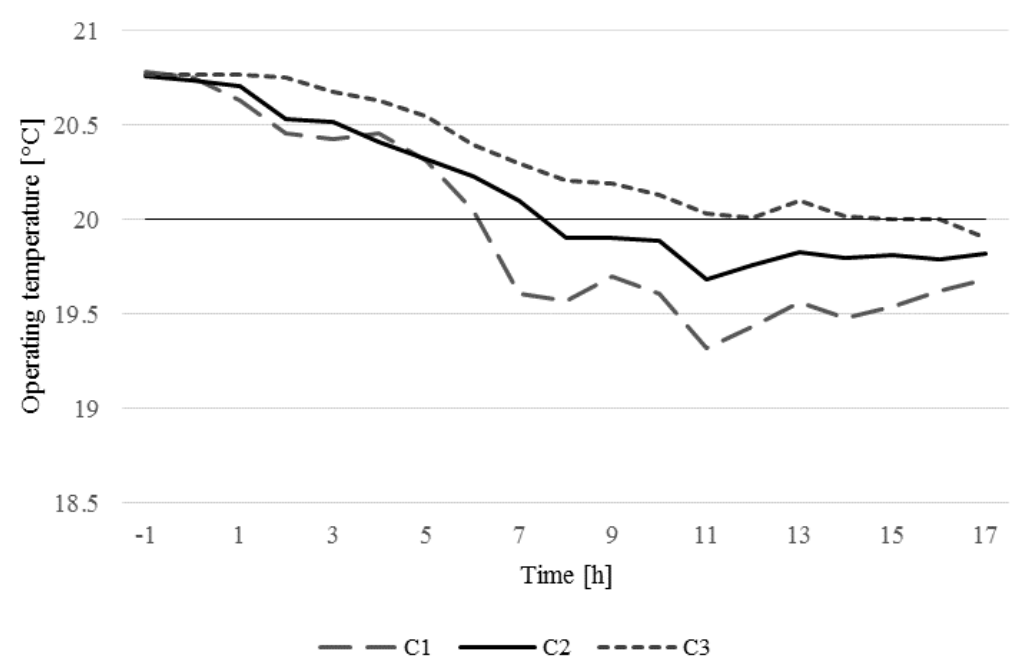

Fig. 5. The effect of thermal inertia on the course of operating temperature 
Operational temperature was determined as the average of the inner air temperature and mean radiant temperature, whereas the mean radiant temperature was simplified consider by the one as an average temperature of all the internal surfaces of building structures. The findings mentioned above might serve as important inputs for the proper and precise control systems design. The heat demand during the day cannot be correctly predicted without this knowledge [11].

\section{Conclusion}

The results of this analysis apply only to climatic conditions that have similar historical course of outside air temperature rate. The paper deals with the effect of passive means against sudden fluctuations internal operating temperatures. The aim is to minimize the risk of subcooling or overheating of structures.

The simulations of the internal environment shows that the operating temperature oscillates due to thermal loads. Thermal accumulation properties of the structures are trying react to these changes by release or absorb heat. During the short-term heat accumulation is construction not able to absorb the heat gains to its full depth. This means that the heat accumulation is involved only a certain part of the surface structure.

Effect of heat accumulation on total energy consumption for conservation acceptable indoor climate conditions also greatly depends on the building use (varying intensity of ventilation, use of various shielding elements). Current technologies allow a wide range of networking the various elements of technology, including access to the Internet. This procedure ensures that the desired temperature is reached by exerting the least possible amount of energy. Knowledge of the issues on thermal mass in buildings with relation to heat accumulation heating systems creates suitable condition for efficient detection of the desired thermal condition of the internal environment, which determines sizing of heating systems, heat sources and optimizing the overall heat consumption. This study will be continued and extended to more complex types of buildings in the aim to obtain the suitable means for an optimal architectural and technological design of buildings from the point of view of energy consumption optimisation

\section{Acknowledgements}

This work was supported by the Ministry of Education, Youth and Sports of the Czech Republic within the National Sustainability Programme project No. LO1303 (MSMT-7778/2014).Work was also supported in frame of Internal Grant Agency of Tomas Bata University in Zlin, Faculty of Applied Informatics No. IGA/CEBIATech/2015/041 and IGA/FAI/2015/023.

\section{References}

[1] ASTE, Niccolo`, Adriana ANGELOTTI a Michela BUZZETTI. The influence of the external walls thermal inertia on the energy performance of well insulated buildings. In: Energy and Buildings. Milano, Italy: 2009, s. 7. 41. ISSN 0378-7788.

[2] Řehánek, Jaroslav. Heat accumulation of buildings. 1. vyd. Praha: ČKAIT, 2002, 276 s. ISBN 80-863-6459-3.

[3] Drábek, P.,Zálešák, M., Some aspects of the impact of building automation on energy efficiency of buildings.Recent Advances in Systems. Proceeding of the 19th International Conference on Systems part of CSCC "15 Zakynthos Island Greece. ISBN: 978-1-61804-321-4.

[4] M. Zálešák, V. Gerlich, In buildings as a necessary mean to achieve assumed energy savings, TOB 2013, č. 16.

[5] EVANGELISTI, Luca, Gabriele BATTISTA. Influence of the Thermal Inertia in the European Simplified Procedures for the Assessment of Buildings' Energy Performance. In: Sustainability. 2014, s. 11. ISSN 2071-1050.

[6] EN ISO 13786. Thermal performance of building components - Dynamic thermal characteristics - Calculation methods. Brusel: European Committee for Standardization, 2007.

[7] DUŠKA, Michal. Heat accumulation in the calculation of thermal load of conditioned space. Praha, 2010. Dissertation. ČVUT.

[8] DI PERNA, C., F. STAZI, URSINI CASALENA a M. D’ORAZIO. Influence of the internal inertia of the building envelope on summertime comfort in buildings with high internal heat loads. Energy and Buildings. 2010, (43).

[9] Koláček, M.,Zálešák, M.The measurement and application of the thermal panel based on a phase change materials.Recent Advances in Systems. Proceeding of the 19th International Conference on Systems part od CSCC "15 Zakynthos Island Greece. ISBN: 978-1-61804-321-4.

[10] EN 12831. Heating systems in buildings: Method for calculation of the design heat load. Brusel: European Committee for Standardization, 2005.

[11] EN ISO 13792. Thermal performance of buildings: Calculation of internal temperatures of a room in summer without mechanical cooling. Brusel: European Committee for Standardization, 2005.

[12] BOND, Danielle E.M., William W. CLARK a Mark KIMBER. Configuring wall layers for improved insulation performance. Applied Energy. 2013, 12(112): 5. ISSN 0306-2619. 